\title{
Long-term Application of Carbon Fiber Composite Cable Tendon in the Prestressed Concrete Bridge - Shinmiya Bridge in Japan
}

\author{
Hue Thi Nguyen ${ }^{1}$, Hiroshi Masuya ${ }^{2}$, Tuan Minh Ha ${ }^{2}$, Saiji Fukada ${ }^{2}$, Daishin Hanaoka ${ }^{3}$, Kazuhiro Kobayashi ${ }^{4}$ and Eiji Koida ${ }^{5}$ \\ ${ }^{1}$ Graduate School of Natural Science and Technology, Kanazawa University, Ishikawa, Japan \\ "ThuyLoi University, 175 Tay Son, Dong Da, Hanoi, Vietnam \\ ${ }^{2}$ Institute of Natural Science and Technology, Kanazawa University, Ishikawa, Japan \\ ${ }^{3}$ Kanazawa Institute of Technology, Ishikawa, Japan \\ ${ }^{4}$ P.S Mitsubishi Construction Co., Ltd., Ishikawa, Japan \\ ${ }^{5}$ Tokyo Rope Manufacturing Co., Ltd., Tokyo, Japan
}

\begin{abstract}
Carbon fiber reinforced plastic (Carbon Fiber Composite Cable, CFCC) has the outstanding features in comparison with regular steel. In October 1988, CFCC was applied as the tensioning material in main girders of new Shinmiya Bridge in Ishikawa, Japan. This was the first bridge in Japan and in the world, which CFCC tendons were used in the prestressed concrete bridge to counter salt damage. To investigate the serviceability and durability of the main girders and CFCC, three full-scale test girders were fabricated in 1988. At the same time, a bending experiment was conducted on one girder to investigate the ultimate behavior, load carrying capacity of the PC girder, as well the strain behavior of the CFCC. Besides, two PC girders were placed next to the main girders of the bridge in the same conditions. One of them was used for a destructive test after six years of the construction time (1994). In this study, another test specimen that was exposed to the actual corrosive environment after nearly 30 years was subjected to a destructive test by bending load. The load carrying capacity of the girder was clarified, and the durability of the PC girders using CFCC tendon was confirmed.
\end{abstract}

\section{Introduction}

The bridges in the coastal area of the Noto Peninsula, Hokuriku region (including Toyama, Ishikawa and Fukui Prefecture) are significantly affected by the flying salinity on the seasonal wind from the Northwest in Japan. As consequences, the deterioration in these bridges due to salt damage is a remarkable problem (see Figure 1). The old Shinmiya Bridge was a reinforced concrete bridge, which had been damaged by salt corrosion. Therefore, the construction of a new bridge became necessary after twelve years of the construction time.

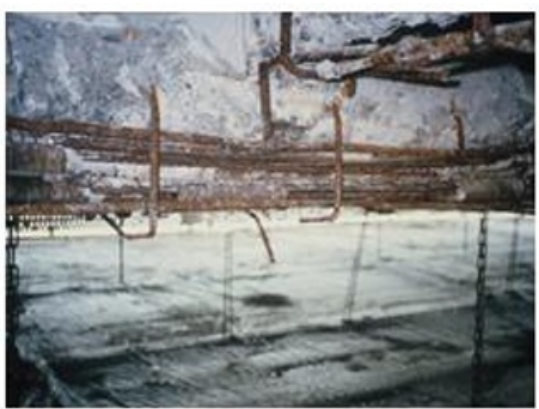

Figure 1. Salt damage due to flying salinity in Hokuriku region.

However, research of Carbon Fiber Reinforced Plastic (CFRP) had started in architectural engineering and civil engineering field from the 1980s in Japan, CFRP was applied as a new material in an alternative to the conventional steel [1]. Carbon Fiber Composite Cable (CFCC) was manufactured and developed by Tokyo Rope Manufacturing Company, Ltd. It is a type of CFRP so CFCC had the similar characteristics of CFRP. CFCC has the outstanding features in comparing with normal steel, it has not only excellent characteristics such as corrosion resistance, lightweight, high tensile strength, high elastic modulus but it was also low relaxation loss, high fatigue strength, low linear expansion and easily coiled flexibility [2].

Therefore, CFCC was selected as the first material for tendons in pre-tensioned prestressed concrete slab system of new Shinmiya Bridge in October 1988. This was the first bridge in Japan and in the world using CFCC tendons in main girders against the salt damage [3]. After that, many of bridge structures were built with this technique in Japan [4]. Furthermore, CFRP was studied and applied not only in Japan but also in other countries in the world [5]. In Canada, the Bendding Trail Bridge was built as the first bridge prestressed with CFCC tendons and Leadline strands in November 1993 in Calgary, Alberta [6]. Abdelrahman and Rizkalla (1997) also conducted the other study about the flexural behavior of concrete beams prestressed by CFRP reinforcement in Canada. The T beams with $6.2 \mathrm{~m}$ in length and $330 \mathrm{~mm}$ 
in depth were used, and the CFRP bars had a diameter of $8 \mathrm{~mm}$, the tensile strength of $1970 \mathrm{MPa}$, and elastic modulus of $147 \mathrm{GPa}$ was applied [7]. In the United States, the Bridge Street Bridge was built in Southfield, Michigan in 2001. It was the first bridge in the USA for using CFCC tendon in $\mathrm{T}$ beam and the monitoring systems will be used until 2020 to confirm the long-term value [8]. Besides, the first CFRP application for the a prestressed girder in road-bridge in Belgium was in 2004. Carbon fiber polymer wires were used with $5 \mathrm{~mm}$ in the diameter, $2450 \mathrm{MPa}$ in tensile strength and $160 \mathrm{GPa}$ in Young's modulus for a T beam [9]. And more than 140 structures applied CFCC as reinforced material as shown by Enomoto et al. (2012), which confirmed that CFCC was suitable for the bridge construction [10].

CFCC has the excellent properties for prestressed concrete bridges but CFCC has not been widely applied in the world due to the cost and uncertain durability. However, in 2012, Grace et al. showed that despite the higher initial cost of CFRP purchasing, the life cycle cost of the bridge was not high when compared to traditional steel reinforced bridges. The cost of CFCC will become the least expensive option after 20-40 years of service time[11]. Regarding the durability, there was only a limited data on the long-term value of prestressed concrete bridges using CFCC tendon, especially the structure has full-scale and was exposed to the actual corrosive salt environment.

In the first bridge in the world using CFCC tendonsShinmiya Bridge, the aim of investigation the durability and serviceability of the main girders using CFCC tendon was performed from the construction time (1988). Three test girders with the same size of the main girders were fabricated in 1988. At the same time, in order to investigate the ultimate behavior and load carrying capacity of the PC girder using CFCC as tendon, a bending experiment was conducted on one girder [12], and the deflection of the main girder, and the strain behavior of the CFCC were shown [13]. Two other PC girders (mountainside, seaside) were placed next to the main girders of the bridge in the same conditions for confirming the long-term quality. Six years after the construction time (1994), the destructive test was carried out using the seaside girder, the comparison of the load carrying capacity with the value in the time of construction was done, and the durability of the CFCC tendon have been confirmed [14]. In this study, a destructive bending test was conducted on the mountainside girder, which was exposed to an actual corrosive salt environment for nearly 30 years (2017), and the results of the load carrying capacity and durability have been evaluated and shown.

\section{Description of Shinmiya Bridge}

The Shimiya Bridge was built at the Shika-machi, Hakuigun, Ishikawa Prefecture, Japan in October 1988. Figure 2 and Figure 3, respectively show the side view and cross-section of Shinmiya Bridge. The bridge had $6.1 \mathrm{~m}$ in length and $7.0 \mathrm{~m}$ in the effective width.

The main bridge has a structure, in which 24 main girders as shown in Figure 3 with the I-shaped cross- section (JIS A 5313, S106-325) shown in Figure 4. For the aim of confirming the long-term quality, two fullscale test girders on both sides of the bridge (mountainside, seaside) were fabricated, and transversely tightened together with the main girders in the same environment. When six years passed (1994) after construction, the test girder on the seaside was taken out. The destructive experiment of this girder by bending load was conducted. And transmission length test, salinity measurement, tensile test and chemical composition test were done after removing of tension by CFCC [14]. In this research, other test girder on the mountainside was removed from the main bridge and the destructive experiment of the girder by bending load was conducted.

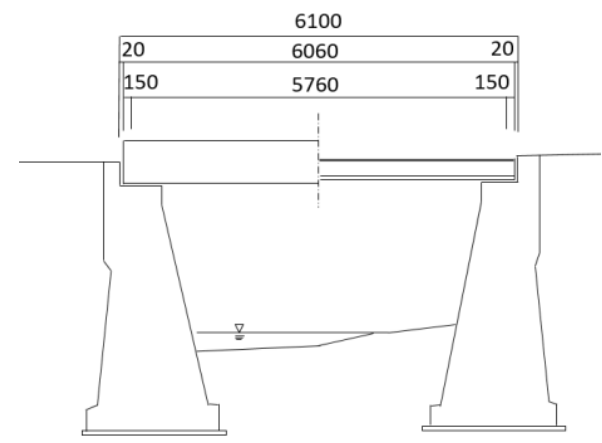

Figure 2. Side view of Shinmiya Bridge (unit:mm).

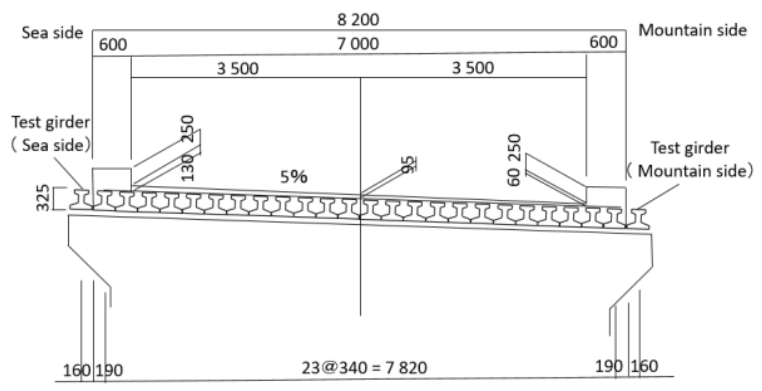

Figure 3. Cross-section of Shinmiya Bridge (unit:mm).

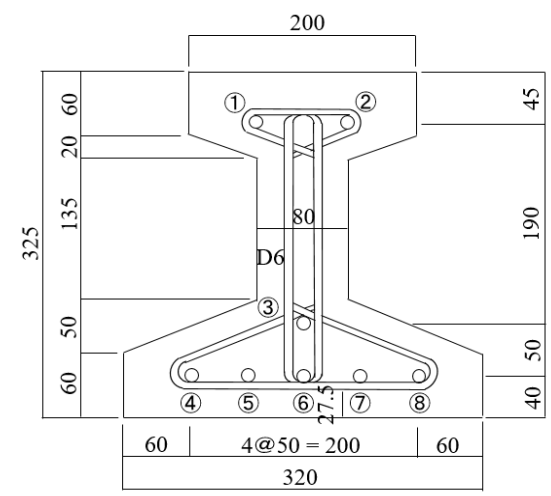

Figure 4. Cross-section of main girder (unit: mm) (o: CFCC).

With respect to the test specimen, the detailed dimension of the mountainside girder was shown in Figure 2, Figure 3 and Figure 4. The length of the test girder was $6060 \mathrm{~mm}$, the height of it was $325 \mathrm{~mm}$ while the width of the top flange was $200 \mathrm{~mm}$, and the width of the bottom flange was $320 \mathrm{~mm}$. The compressive strength of concrete in the past was recorded of $59.8 \mathrm{~N} / \mathrm{mm} 2$. The 
stirrup used epoxy coated rebar of D6 as a method against salt damage. Eight straight CFCCs (Carbon Fiber Composite Cable) with a diameter of $12.5 \mathrm{~mm}$, and seven strands were employed for tendons. The surface of CFCC tendons were twisted and roughened to enhance the adhesion effect with concrete

\section{Bending test}

\subsection{Outline of experiment}

The destruction test by bending load was conducted according to the same method of the test, which was done at six years passed after construction. The outline and the test setup of bending experiment are shown respectively in Figure 5 and Figure 6. The load was applied at the two points in the middle of the span with a distance of 1000 $\mathrm{mm}$ and two steel rollers supported for the girder. Measuring items including load, displacement, and strain at the center and at the support positions of the main girder were arranged as the Figure 7.

The loading procedure was the same as $t$ that was done in the loading test at six years passed after construction. First, the load was applied up to $35.4 \mathrm{kN}$ (design load $35.3 \mathrm{kN}$ ) and returned to $0 \mathrm{kN}$. Secondly, the load was loaded to crack initiation load and returned to 0 $\mathrm{kN}$ again. Finally, load was loaded to the ultimate load as the final stage.

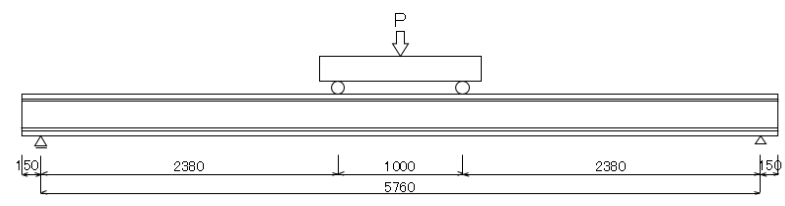

Figure 5. The outline of experiment.

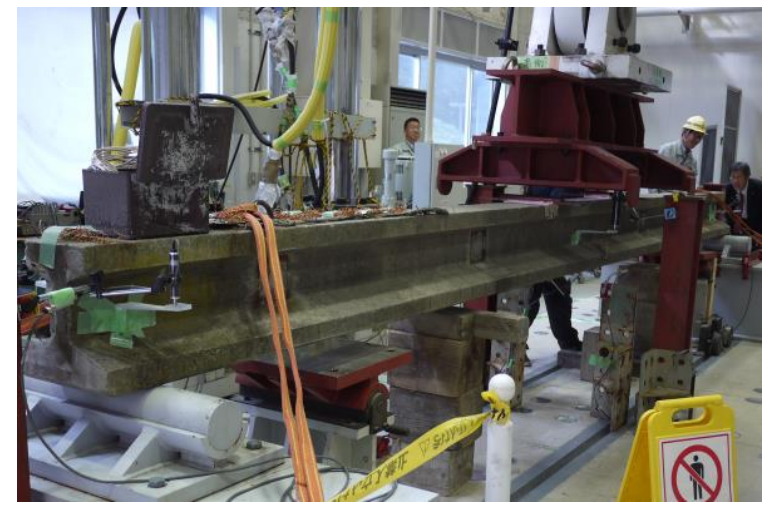

Figure 6. The setup of bending experiment.

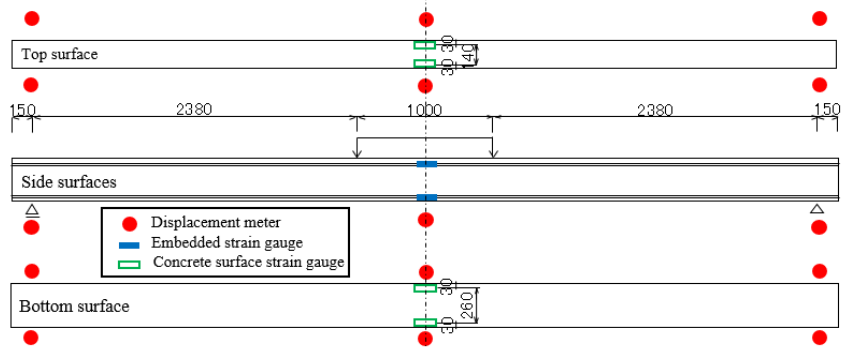

Figure 7. Measurement positions.

\subsection{Flexural behavior}

The situation of the PC girder after failure is shown in Figure 8 . The relationship between load and displacement at the middle of the span, the relationship between load and strain, and the crack pattern obtained by the destructive test are shown in Figure 9, Figure 10 and Figure 11, respectively. In addition to the results of this loading test, crack initiation load and bending fracture load at the time of construction, six years after construction, and design values are summarized in Table 1.

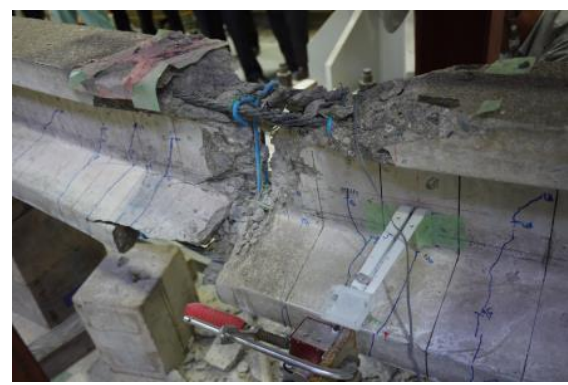

Figure 8. The situation of the girder specimen after failure.

Table 1. Comparison of crack initiation load and ultimate load.

\begin{tabular}{|l|l|l|c|c|}
\hline & \multirow{2}{*}{$\begin{array}{c}\text { Design } \\
\text { value }\end{array}$} & \multicolumn{1}{|c|}{$\mathbf{1 9 8 8}$} & $\mathbf{1 9 9 4}$ & $\mathbf{2 0 1 7}$ \\
\cline { 3 - 5 } & & $\begin{array}{c}\text { At the time } \\
\text { of } \\
\text { construction }\end{array}$ & $\begin{array}{c}\text { After } \\
\mathbf{6} \\
\text { years }\end{array}$ & $\begin{array}{c}\text { After } \\
\mathbf{2 9} \\
\text { years }\end{array}$ \\
\hline $\begin{array}{l}\text { Cracking initiation } \\
\text { load (kN) }\end{array}$ & 68.3 & 70.6 & 98.3 & 82.8 \\
\hline Ultimate load $(\mathbf{k N})$ & 131.2 & 132.3 & 167.1 & 157 \\
\hline
\end{tabular}

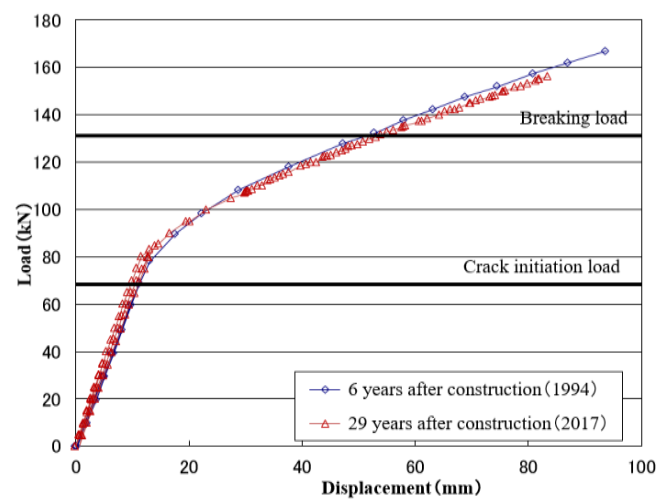

Figure 9. Relationship between load and displacement at midspan.

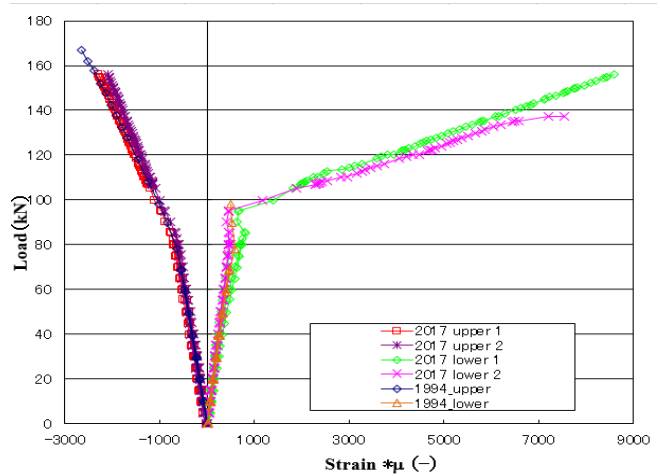

Figure 10. Relationship between load and strain of concrete. 


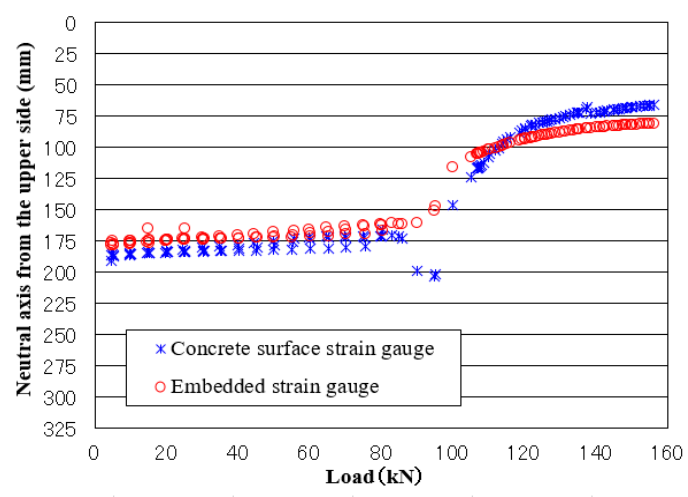

Figure 11. The neutral axis depth.

The failure mode imposed in this loading test was the crushing of concrete in the compressive area after the bending crack propagation (see Figure 8). This occurred because the CFCC had no yield phenomenon, the girder was designed to be a destructive form, which the top flange of the concrete collapsed before CFCC ruptured. In this experiment, the destruction was as the same with design. This destruction was similar to that obtained in the tests at the time of construction time and six years after construction.

The situation of the PC girder surface after the concrete collapse and CFCC after the destruction test were observed. It was found that the CFCC in the upper side was twisted and ruptured after crushing of the concrete. However, at the CFCC of the lower side, failure due to tension could not be confirmed.

\subsection{Load-displacement relationship}

From the relationship of load-displacement shown in Figure 9, when the load was unloaded after loading up to design load and crack initial load, almost no residual defection was observed. The relationship of loaddisplacement obtained by this examination was overlapped with the results at the time of six years passed after construction.

This relationship was the linear until the initial crack occurred at the load of $82.8 \mathrm{kN}$ (approximately 50 percent of the final load). In comparing with the applied load of the six years after construction time, the initial crack load decreased by $15.7 \%$ but this number was also higher than the design value $(68.3 \mathrm{kN})$. In addition, the ultimate load and the mid-span displacement were 157 $\mathrm{kN}$ and $84 \mathrm{~mm}$, respectively. The value of final load reduced by about $6 \%$ as compared with the result obtained in the bending test in 1994 (six years after construction time). However, as shown in Table 1 this result was superior to the value at the construction time $(132.3 \mathrm{kN})$ and the design value $(131.2 \mathrm{kN})$. These results revealed that there was no problem in term of the load carrying capacity of the main girder.

\subsection{Strain distribution}

As can be seen from the Figure 10, the relationship between applied load and strain obtained by this experiment was close to the results in 1994.

Figure 12 shows the results of neutral axis depth calculated from the concrete surface strain gauge and embedded strain gauge. It assumed the linear distribution of strain in the cross-section for the neutral axis calculation. In the elastic stage, the neutral axis depth was almost similar between two results. After $82.8 \mathrm{kN}$, the values of neutral axis were a slight difference but both of them had the trend toward the compression zone with an increase of the applied load. This difference may be due to one of the concrete surface strain gauges on the lower side that was broken before ultimate load and the strain distribution on the cross-section was not linear. In term of the result calculated from embedded strain gauge, the strain of concrete at the middle span was 0.0011 in compression and 0.0060 in tensile at failure. The neutral axis depth of test girder was approximately $81 \mathrm{~mm}$ at $156.2 \mathrm{kN}$

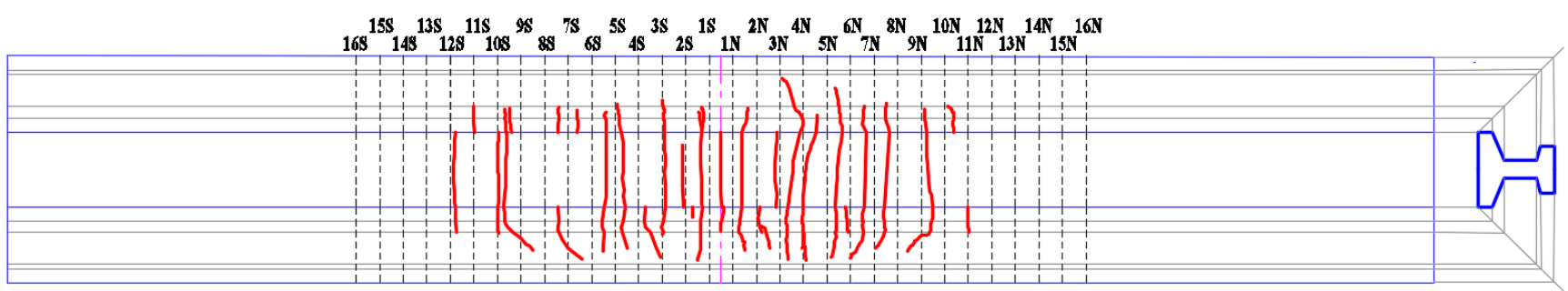

Figure 12. The neutral axis depth.

\section{Conclusions}

The first destructive experiment was conducted on the full-scale PC girder using CFCC tendons, which was exposed for approximately 30 years in the actual corrosive salt environment. The durability and load carrying capacity of PC girder were clarified. The remark conclusions were given follow.

- The mode of failure in this study was the crushing of concrete followed by the rupture of CFCC tendon in the compression zone. The result was similar to the failure modes in the construction time (1988) and six years after construction time (1994).

- The cracks occurred mainly in the middle of girder zone. It began in the bottom of flange toward the loading points.

- From the results of the comparison regarding the load-displacement relationship, load-strain relationship obtained by the destructive bending test and the experiment at six years after construction, it has become clear that there was no significant 
difference in the shape of relationship curves. Although, the ultimate load in this experiment was about $6 \%$ lower than the data at six years after construction. However, this value was also higher than the design value. It was judged that there was no problem in load carrying capacity after nearly 30 years.

- From the results of previous studies and this outcome, it can said that CFCC is suitable to replace the regular steel in bridges, especially the prestressed concrete bridges constructed in corrosive environments to combat salt damage.

- Furthermore, with the reasonable cost and the durability confirmed, CFCC should be studied and applied more in the field of architectural engineering and civil engineering worldwide

\section{Acknowledgment}

This research was conducted as part of the Crossministerial Strategic Innovation Program (SIP). (R \& D subject: Resolution of Early-aged Deterioration Mechanisms in Concrete Bridges and Development of Total Management System Based on Evaluation for Material and Structure Quality Performance, Chairman: Kazuyuki Torii). We are deeply grateful to everyone concerned and supported

\section{References}

1. JSCE, Recommendation for design and construction of concrte stuctures using continuous fiber reinforcing materials,(1998).
2. H. Kimura, N. Shiratori, and H. Takagi, Concr. Eng. Annu. Rep. 12-1PP (1990) (in Japanese)

3. N. Santoh, H. Kimura, T. Enomoto, T. Kiuchi, and Y. Kuzuba, Fiber-Reinforced-Plastic （ FRP ） Reinforcement Concr. Struct. Proc. Int. Symp. ACI, SP-138, pp. 895 - 911 (1993)

4. V. M. Karbhari, Int. Technology Research Institute, (1998).

5. P. B. Potyrała, Thesis, (2011)

6. S. H. Rizkalla and G. Tadros, Concr. Int., vol. 6, no. 4, pp. 37-42, (1994)

7. A. A. Abdelrahman and S. H. Rizkalla, ACI Struct. J., no. 94, pp. 447-454, (1998)

8. N. F. Grace, F. C. Navarre, R. B. Nacey, W. Bonus, and L. Collavino, PCI Journal, 47 5, pp. 20-35., (2002)

9. W. D. Corte and P. Van Bogaert, Compos. Part B Eng., vol. 36, no. 2, pp. 91-98 (2005)

10. T. Enomoto, N. F. Grace, and T. Harada, Proc., Conf. FRP Compos. Civ. Eng., vol. Rome Italy (2012)

11. N. F. Grace, E. Jensen, C. Eamon, T. Enomoto, and X. Shi, Proc. CICE 2012 6th Int. Conf. FRP Compos. Civ. Eng., pp. 1-8 (2012)

12. T. Yamashita, T. Kiuchi, H. Inukai, and T. Iwasaki, Prestress. Concr. Vol. 31, No.2, pp. 71-78 (1989) (in Japanese)

13. T. Futakuchi, S. Komada, T. Kiuchi, and K. Matsumoto, Proc. 2nd Symp. Prestress. Concr. Tech. Assoc. pp. 307-310 (1991) (in Japanese)

14. H. Kanda, T. Kiuchi, and K. Matsumoto, Proc. 5th Symp. Prestress. Concr. Tech. Assoc., pp. 529-532, (1995) (in Japanese) 